\title{
A construção da proximidade na comunicação pública: mídia social e a ruptura da impessoalidade
}

The construction of proximity in public communication: social media and the rupture of impersonality

La construcción de la proximidad en la comunicación pública: medios sociales y la ruptura de la impersonalidad

\section{Márcio Simeone Henriques}

- Pós-doutor pela Universidade Nova de Lisboa, Portugal

- Doutor em Comunicação Social pela Universidade Federal de Minas Gerais (UFMG)

- Mestre em Educação pela Universidade Federal do Rio de Janeiro (UFRJ)

- Professor adjunto do Departamento de Comunicação Social e do Programa de Pós-Graduação em Comunicação Social da UFMG

- $\quad$ Líder do grupo de pesquisa "Comunicação, mobilização social e opinião pública - Mobiliza", da UFMG, e membro do grupo de pesquisa "Comunicação no contexto organizacional: aspectos teóricos e conceituais" (PUC-Minas)

- E-mail: simeone@ufmg.br

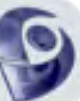

\section{Lidiane Ferreira Sant'Ana}

- Mestre em Comunicação Social - Interações Midiáticas pela Pontifícia Universidade Católica de Minas Gerais (PUC-Minas)

- $\quad$ Especialista em Jornalismo: práticas contemporâneas pela PUC-Minas

- Graduada em Relações Públicas

- Membro dos grupos de pesquisa "Comunicação no contexto organizacional: aspectos teóricos e conceituais" (PUC-Minas/CNPq) e "Campo comunicacional e suas interfaces" (PUC-Minas/ Fapemig)

- E-mail: lidianefsantana@gmail.com.br 


\section{Resumo}

Discute-se o uso da internet na comunicação pública, com base no caso da Prefeitura de Curitiba. Analisa-se a mídia social gerida pelo governo local como meio de aproximação com a sociedade, em suas possibilidades e limites. Em visão comparativa com órgãos semelhantes no Brasil e no exterior, busca-se entender como uma instituição burocrática e impessoal constrói uma identidade e conquista espaço de fala em um meio de comunicação cuja principal característica é a proximidade.

\section{PALAVRAS-CHAVE: COMUNICAÇÃOO ORGANIZACIONAL・COMUNICAÇÃO PÚBLICA・MÍDIAS SOCIAIS・ENGAJAMENTO.}

\section{Abstract}

One discusses the use of the Internet in public communication, based on the case of the Municipal Government of Curitiba, Brazil. One analyzes the social media managed by the local government as a means of getting closer to the society, within its possibilities and limits. In a comparison with similar agencies in Brazil and abroad one seeks to understand how a bureaucratic and impersonal institution builds an identity and gains speaking space in a means of communication the main characteristic of which is proximity.

\section{KEYWORDS: ORGANIZATIONAL COMMUNICATION •PUBLIC COMMUNICATION・SOCIAL MEDIA・COMMITMENT.}

\section{Resumen}

Se discute el uso de internet en la comunicación pública, basados en el caso de la Alcaldía de Curitiba. Se analiza los medios sociales administrados por lo gobierno local como medio de aproximación con la sociedad, en sus posibilidades y límites. En una perspectiva comparativa con órganos semejantes en el Brasil y en el exterior, se busca entender cómo una institución burocrática e impersonal construye una identidad y conquista espacio comunicativo en un medio de comunicación cuya principal característica es la proximidad. 
á é sabido que as mídias sociais modificam a forma de interação entre os sujeitos do processo de comunicação, podendo torná-lo mais interativo e participativo. Entendidas por Elizabeth Saad Corrêa (2009) como "quaisquer tecnologias ou práticas on-line que permitem o compartilhamento de conteúdo, opiniões, ideias, experiências e mídias, possibilitando conversações sobre o que é relevante", elas disponibilizam os mesmos recursos comunicativos a todos os interagentes.

A presença de instituições nas mídias sociais é uma possibilidade de trabalhar a legitimidade não apenas a partir do discurso em torno da própria imagem, mas do diálogo e do debate acerca das questões que a estruturam. Nesse ambiente, há novas possibilidades, tanto em termos de visibilidade quanto de avaliação e gestão das relações. No entanto, quando se fala em exposição institucional em mídias interativas onde há hiperconectividade, tende a emergir o conflito entre os benefícios e riscos da visibilidade e a perda do controle, próprio da zona de conforto da comunicação unilateral, como também inúmeras contradições relativas a questões como o tom mais formal ou informal ou o grau de aprofundamento do conteúdo.

As mídias sociais mediadas por computador evocam a ideia de uma comunicação dirigida aproximativa, apresentada por Margarida Kunsch (2003). Considera ela que, tal como ocorre na comunicação face a face, as mídias sociais possibilitam ações interativas das organizações com públicos identificados, cujo feedback pode ser imediato. Isso remete ao problema de avaliar que em que termos essa relação potencialmente interativa ocorre e quais suas perspectivas.

Algumas experiências têm chamado a atenção para aspectos cruciais desse tipo de interação, como é o caso da fan page da Prefeitura de Curitiba no Facebook. Criada em março de 2013, em quase dois anos de existência atraiu um público de mais de 470 mil seguidores. Ao centrar suas estratégias na valorização de aspectos relacionais próprios de plataformas das mídias sociais digitais, como o Facebook, a iniciativa rompe com o modelo de comunicação formal e austera, típico desse tipo de instituição, inclusive nas mídias sociais.

Dessa forma, realizamos um estudo de caso exploratório, de modo a analisar tanto aspectos discursivos quanto as relações que se estabelecem. Para avaliar que tipo de postagem mais repercute entre os fãs, foram reunidos dados estatísticos da fan page, por meio do aplicativo Netvizz. 0 formato do post, por quem foi feito (se pela página ou por tagueamento), sua mensagem, data e horário de publicação, o número de curtidas, comentários e compartilhamentos, taxa de engajamento e seu link, são os dados captados pelo aplicativo e ordenados em uma planilha. Para fins comparativos, também foram levantados os índices de engajamento na fan page de prefeituras de outras capitais do Brasil e de outros países.

Diante de tamanho dinamismo das redes, dados quantitativos são úteis, mas insuficientes para entender aspectos subjetivos do discurso. Portanto, além da avaliação das métricas, a análise da forma de construção das mensagens foi utilizada como um caminho para entender como o envolvimento é cultivado e quais seus efeitos, a partir de uma perspectiva de conteúdo, linguagem e contexto.

A fan page da Prefeitura de Curitiba no Facebook (www.facebook.com/PrefsCuritiba) é a página que reúne o maior número de seguidores entre as fan pages de capitais de estados brasileiros, tendo mais que o dobro de curtidas que a segunda colocada, a fan page da Prefeitura de Manaus, com 197 mil seguidores.

0 que nos instiga nessa análise é entender os meandros do massivo interesse, inclusive dos que moram em outras partes do país, pelo que a Prefeitura de Curitiba tem a dizer na rede social e a forma como interagem e se relacionam com ela. Diante de um objeto que faz emergirem diversas perguntas relacionadas à comunicação pública, propomos nos ater às seguintes questões: 1) quais elementos comunicacionais são utilizados para gerar e manter o engajamento? 2) qual é a dinâmica interacional desse processo? 


\section{o ÍNDICE DE ENGAJAMENTO SOB UMA PERSPECTIVA COMPARATIVA}

0 engajamento indica o quanto as mensagens chamam a atenção dos seguidores da fan page e é também uma janela que mostra o conteúdo para quem está fora da página. Ele pode ser avaliado tanto em termos de postagens específicas, quanto da página. 0 cálculo em relação à página, além da soma de curtidas, comentários e compartilhamentos, utilizados para as postagens, inclui links e menções a ela e é feito a partir do número de pessoas "falando sobre isso", dividido pelo total de fãs.

Com 475.661 fãs e 86.888 pessoas interagindo e citando sua fan page, a Prefeitura de Curitiba possui 0 índice mais alto de engajamento entre as capitais de estados brasileiros com os maiores números de fãs, conforme detalhado na Tabela 1. Os dados, também, dão destaque a outra questão relevante. A Prefeitura de Recife demonstra que a quantidade de fãs não é proporcional ao engajamento da página. Ou seja, o número de pessoas que curtem a página não é o fator mais relevante para a repercussão do conteúdo. Quarta colocada em número de curtidas, ela é a que tem o segundo maior índice de engajamento, distanciando-se de Curitiba por apenas 0,03 pontos'.

Tabela 1 - Fan pages de capitais brasileiras

\begin{tabular}{|c|c|c|c|}
\hline Capital & Fãs da página & Pessoas falando & Engajamento \\
\hline Curitiba & 475.661 & 86.888 & 0,18 \\
\hline Recife & 138.350 & 21.170 & 0,15 \\
\hline São Luiz & 116.957 & 8.814 & 0,07 \\
\hline Manaus & 197.638 & 12.356 & 0,06 \\
\hline Maceió & 189.591 & 7.953 & 0,04 \\
\hline Rio & 129.513 & 2.156 & 0,01 \\
\hline
\end{tabular}

Fonte: os autores.

Ampliando a amostragem comparativa para páginas de prefeituras de cidades de outros países (Tabela 2), a fan page da Prefeitura de Lisboa chama atenção ao alcançar 0,29 de índice de engajamento. As de Barcelona e de Mendoza também têm os mais altos índices, respectivamente 0,14 e 0,17, enquanto Boston possui 0,04 e Nova York tem 0,009. Embora a amostragem seja limitada para permitir generalizações, ela é útil como parâmetro para os índices gerais obtidos no Brasil.

Tabela 2 - Fan pages de cidades estrangeiras

\begin{tabular}{|c|c|c|c|}
\hline Cidade & Fãs da página & Pessoas falando & Engajamento \\
\hline Lisboa & 96.124 & 27.876 & 0,29 \\
\hline Mendoza & 75.785 & 12.883 & 0,17 \\
\hline Barcelona & 133.782 & 18.764 & 0,14 \\
\hline Boston & 29.526 & 1.409 & 0,04 \\
\hline Nova York & 325.161 & 3.126 & 0,009 \\
\hline
\end{tabular}

Fonte: os autores.

1 Dados coletados no dia 25 de fevereiro de 2015 
$\mathrm{Na}$ amostra nacional e estrangeira, identificamos, portanto, outras quatro prefeituras que se destacam pelo engajamento: Lisboa $(0,29)$, Mendoza $(0,17)$ Recife $(0,15)$ e Barcelona $(0,14)$. A primeira, marcada por um tom informal, faz uso intenso de imagens nas postagens, além de gírias, regionalismos e chamadas para envio de fotos e opiniões. A página portuguesa, destaque dentre todas as prefeituras pesquisadas, adota linguagem e conteúdo sisudos. Ela faz uso intenso de fotos da cidade, sendo estas quase que exclusivamente as imagens utilizadas pela página, inclusive para saudações de bom dia e boa noite. 0 emprego da hashtag Lisboa também é bastante recorrente.

A fan page da prefeitura da cidade argentina Mendoza, possui o índice de engajamento mais próximo do registrado em Curitiba, diferenciando-se por apenas 0,01 ponto a menos. Além de utilizar fotos da cidade para desejar bom dia e boa noite, ela posta recorrentemente fotos de servidores municipais trabalhando, para divulgar a execução de obras e atividades diversas. Também faz uso intenso de hashtagse links. Barcelona tem como grande foco a linguagem audiovisual, sobretudo com conteúdo de promoção da cidade. Em comum entre todos esses destaques, está o emprego de um tom de conversa que vai da saudação amigável às sugestões de passeios e perguntas sobre temas diversos, com o uso recorrente de imagens.

\section{A CONSTRUÇÃO DO ENGAJAMENTO: ASPECTOS DISCURSIVOS E RELACIONAIS}

0 alto número de curtidas, bem como de engajamento do público na página da Prefeitura de Curitiba, nos motiva a analisar de forma mais específica o que atrai e mantém o interesse do público e investigar o significado do uso estratégico desse recurso.

Para análise foram selecionadas as cinquenta postagens com maior índice de engajamento, dentre as publicações feitas de dezembro de 2013 a fevereiro de 2015. A soma de curtidas, compartilhamentos e comentários totalizou 783.413 ações de engajamento, com postagens que obtiveram de 30.295até10.043 ações dessetipo. Outros dados quantitativos dessaamostragem subsidiarão as discussões que seguem. Embora não sejam contabilizadas as repercussões decorrentes dos compartilhamentos, ou seja, as curtidas, comentários e compartilhamentos feitos a partir da disponibilização da postagem nos perfis daqueles que compartilharam, os dados são relevantes para indicar o impacto direto das mensagens nos seguidores da fan page.

\section{O discurso como gerador de proximidade}

Em uma mídia com tão amplas possibilidades de recursos narrativos, as postagens tendem a percorrer diversas linguagens, propiciadas pela convergência das mídias que, segundo Lucia Santaella (2009), é marca registrada da cultura digital. Além do intenso uso de imagens, sejam fotos, ilustrações ou vídeos, tanto nas postagens quanto nos comentários, e o uso de signos próprios do meio digital, tais como templatestemáticos (Plantão Curitiba, Curitiba Responde) e hashtags, demarcam o espaço de comunicação, a partir de uma lógica própria, característica do meio. Os textos, por sua vez, são curtos. Não raro se limitam a uma frase ou até mesmo a uma ou até três palavras.

Daniela Bertocchi (2006) destaca a hipertextualidade (capacidade de conectar diversos textos digitais entre si), a multimedialidade (capacidade de combinar texto, imagem e som na mesma mensagem) e a interatividade (possibilidade de o usuário interagir com a informação) como características-chave da comunicação nesses meios.

A hipertextualidade é um recurso bastante evidenciado na fan page da Prefeitura de Curitiba, tanto nas postagens quanto nos comentários. 0 uso de links é feito, sobretudo, para outros sites que não o da instituição, além de blogs. A conexão 
com outros ambientes digitais também ocorre por meio da postagem de vídeos de músicas do Youtube e do uso frequente de fotos publicadas no Instagram. Hashtags, hiperlinks indexáveis pelos mecanismos de busca são outros recursos hipertextuais intensamente utilizados. Há ainda uso, sobretudo nos comentários, de tagueamento como forma de vincular o conteúdo da página a outras fontes.

A 11a postagem com maior índice de engajamento exemplifica a repercussão a partir de citações. Um pedido de casamento, feito pela página da Prefeitura do Rio de Janeiro à Prefeitura de Curitiba, tornou-se uma inusitada oportunidade de diálogo entre as fan pages de diversas prefeituras. Manifestações favoráveis e comentários sobre a possibilidade de união se multiplicaram em diversas páginas nas quais a Prefeitura de Curitiba era sempre marcada por tagueamento.

A multimedialidade é verificada no uso de personagens como a capivara, eleita símbolo da cidade, além de personagens de filmes, desenhos animados e jogos para ilustrar ou mesmo serem porta-vozes das mensagens, criando uma intensa intertextualidade. Esse recurso é frequentemente utilizado pela página para surpreender o público com a proximidade de seus heróis, humanizados em cenas e espaços públicos da cidade, a partir de sua sobreposição em fotos. Dentre outros exemplos, destaca-se a veiculação de vídeos em formato de telejornal. 0 Capivara News dá voz a um mascote, que reforça a marca da cidade e da página. Os vídeos produzidos a partir de computação gráfica dividem espaço com as animações que dão vida ao Dr. Sigmundo, porta-voz de dicas de limpeza pública e Vó Gertrudes, uma atriz que encarna uma personagem criada pela prefeitura para abordar questões de trânsito.

Por seu caráter central nessa discussão, a interatividade, entendida como a ação do usuário a partir da mensagem, será abordada de forma mais detalhada a seguir.

\section{Identidade virtual e rapport management}

No meio virtual, os indivíduos que compõem uma rede são identificáveis e diferenciáveis por outros aspectos que não os físicos ou mesmo de identidade reais, mas pela imagem que constroem a partir do que publicam e da forma como se relacionam. Nome, aparência e postura podem ser moldados intencionalmente a partir de recursos próprios desse ambiente. Entendese essa identificação como aspecto essencial para modular a predisposição dos potenciais interagentes em estabelecer algum tipo de aproximação e relacionamento. Raquel Recuero (2009) destaca que é a partir das percepções construídas pelos atores que os padrões de conexões são gerados. Ela chama a atenção para a importância de entender como os atores constroem esses espaços de expressão, para analisar como as interações ocorrem.

Assim, curtir uma página no Facebook corresponde a se predispor a receber suas mensagens, ou seja, demonstra receptividade para comunicar-se e talvez estabelecer um relacionamento. Nessa perspectiva, uma vez captada a atenção e despertado 0 interesse pela página, cultivá-lo requer a geração de um sentimento de proximidade. 0 gerenciamento do relacionamento (rapport management), na perspectiva de Helen Spencer-Oatey (2000), constitui uma estratégia de envolvimento. Para ela, gerenciar o rapport envolve tanto administrar a harmonia quanto a desarmonia entre os interlocutores, ou seja, lidar com as condições conflituosas e harmoniosas nas quais se desenvolverão as interlocuções. Joseph Cappella (1981) afirma que 0 rapporté um processo interacional complexo, conhecido no senso comum como a "química" das relações interpessoais; são comportamentos adotados durante a comunicação, fundamentais para as relações interpessoais e para a manutenção do contato. Aqui ele é entendido, portanto, como a receptividade de cada um ao que o outro tem a dizer, favorecendo a criação de sintonia, de empatia, estabelecendo um esquema mínimo de confiança. 
Considerando-se que a aproximação cria condições para a interação se desenvolver e, eventualmente, se manter, busca-se entender como a Prefeitura de Curitiba se torna a "Prefs" no espaço virtual e quais elementos são utilizados para formatar sua ambiência institucional no Facebook de forma a envolver seus seguidores e adquirir legitimidade.

Em uma página vinculada ao poder executivo, pressupõe-se inicialmente que o engajamento seja promovido a partir da prestação de serviço e participação no debate de temas políticos. Diferentemente do esperado, no entanto, a fan page da Prefeitura de Curitiba adota outros recursos para atrair e envolver seus seguidores. Embora haja algumas manifestações nesse sentido, com campanhas de interesse público e dicas de urbanidade, informes sobre obras, negociações de greves, programação cultural e vagas de emprego (em geral mais na direção da prestação de serviço que do debate), o envolvimento é centrado no conteúdo ameno. Para direcionar demandas de serviços que porventura sejam apresentadas, a página possui um aplicativo de captação, com um formulário próprio.

0 ambiente é moldado para que as pessoas saibam o que podem esperar dele: criatividade e conteúdo inusitado. As mensagens chamam atenção e conquistam admiração e simpatia por terem formato e temas irreverentes. Assim, combinam estratégias típicas do chamado "marketing de guerrilha". "O grande segredo é ter a ousadia sempre pulsante, ser inovador e impactante, para causar expectativa em torno do conteúdo, transmitindo uma atitude latente, gerando mídia gratuita nos demais meios de comunicação massivos", explicam Luana Inocêncio, Acsa Lima e Cândida Nobre (2011), ao analisarem o uso desse tipo de estratégia nas mídias sociais. A linguagem burocrática, marcada pela formalidade e impessoalidade, típica das instituições de governo, dá lugar ao uso de conteúdo e linguagem cotidiana e à informalidade. Assim, a fan page inova ao posicionar-se como "um igual", o que denota sua tática de estabelecer proximidade (e até mesmo intimidade) e, com isso, promover maior engajamento.

Apelidada de Prefs, a Prefeitura de Curitiba assume um discurso cuja linguagem e conteúdo a humanizam, transpondo-a para o cotidiano com mensagens que muitas vezes se resumem a um desejo de boa noite, acompanhado de uma música com link para o Youtube, ou de um convite para apreciar a lua. Um chamado para tirar a roupa do varal, ao anunciar a previsão de chuva, é outra forma de surpreender com o emprego dessa estratégia. Nessa lógica, as previsões do tempo são recorrentemente utilizadas para gerar proximidade. Dentre as cinquenta postagens que geraram mais engajamento, dezesseis (nada menos que 32\%) abordam essa temática. A postagem com maior número de compartilhamentos (5.922) e nona colocada no índice de engajamento, é uma imagem que remete ao filme Frozen e anuncia a chegada do frio à cidade. Marcada pela hipertextualidade, ela recebe um grande número de tagueamentos e hashtags.

Na amostra de cinquenta postagens, 43 possuem imagens, sendo fotos, templates ou vídeo. Entre os que consideramos sem imagens, há dois com o uso de símbolos, ambos com um pequeno coração no final da frase, dois calendários com símbolos do tempo e um texto diagramado de forma estilizada. Somente duas postagens usam exclusivamente texto.

Com essa mesma proposta, a prefeitura posiciona-se como uma amiga em busca de conselhos. "Dias com céu azul e noites com friozinho, edredom e filme. Devemos aceitar esse pedido da Prefeitura do Rio de Janeiro?", pergunta, referindo-se a uma proposta de casamento. 0 público mostrou ter gostado da consulta e não se furtou a opinar. A postagem recebeu 15.773 curtidas, 1.095 comentários e 929 compartilhamentos, fazendo desta a 15a postagem com maior engajamento. "Assim, guerrilha gera um conteúdo, uma história, que tem como foco atingir as pessoas de forma ágil e ousada, envolvendo e engajando-as, estabelecendo uma conversa", reforçam Inocêncio, Lima e Nobre (2011). 
Entendidas como meios de gerar proximidade e familiaridade, tais postagens constituem também recursos para manter ativa a conversação, chamar o público ao diálogo, mesmo que sobre amenidades. Assim, os conteúdos mais "leves" parecem ter a função de manter a conexão bem ao modo cotidiano, como quando tecemos comentários sobre o clima, apenas para iniciar uma conversa. Esse recurso, denominado comunhão fática por Bronislaw Malinowski (1972), é apresentado pelo antropólogo como um ato que serve para estabelecer um laço pessoal, uma preparação para a interação, para gerar "uma agradável atmosfera de intercurso polido, social". Dessa forma, laços de união são criados e cultivados.

As curtidas, meios mais utilizados pelo público para manifestar-se em relação às postagens do Facebook, são um recurso efetivo de manutenção dessa conexão, por parte dos seguidores. Na amostra composta pelas cinquenta postagens que geraram os maiores índices de engajamento, foram registradas 674.772 curtidas, representando $86 \%$ das ações de interação. Raquel Recuero (2014) justifica que "o botão "curtir" parece ser percebido como uma forma de tomar parte na conversação sem precisar elaborar uma resposta". Seu uso é muito mais no sentido de sinalizar que a mensagem foi recebida, manifestar concordância ou mesmo agradecimento, segundo a autora. A praticidade em dar esse feedback certamente é fator preponderante.

Por requererem posicionamento e exposição do participante, os comentários tendem a ser a forma de interação menos recorrente. Na amostra, foram registrados 23.598 comentários (3\%), boa parte deles tendente a focar na criatividade da postagem, mais que no conteúdo da mensagem.

A página também emprega expressões regionalistas e um discurso de exaltação da cidade, como um chamado ao cultivo e à expressão do amor à Curitiba. Ao promover a valorização da cultura local em uma mídia essencialmente desterritorializada, a página marca seu locus físico geográfico de fala e, com isso, correlaciona sua imagem de leveza e simpatia à cidade que representa, promovendo, assim, um trabalho de branding que busca incutir em Curitiba um conceito, uma marca. 0 orgulho de ser curitibano é intensamente trabalhado, criando um apelo afetivo e uma ligação emocional que também possui em certa medida um caráter aproximativo.

0 postintitulado "Jornalista estrangeiro cita 10 coisas que aprendeu com Curitiba" é uma boa amostra do discurso de exaltação da cidade. Feito no dia 24 de junho de 2014, ele é a postagem que obteve maior engajamento, tendo recebido mais curtidas e também mais comentários não só a partir do texto da postagem, como também a partir dos comentários do público. Ao todo, foram 23.822 curtidase 1.359 comentários. No quesito compartilhamento, ficou em terceiro lugar, com5.114 compartilhamentos.

Não raro os "fãs", verdadeiros admiradores e advogados da página, tendem a replicar os conteúdos, tornando-se porta-vozes dispostos a vincularem seu perfil à marca Prefs e reverberar suas falas por meio de comentários e compartilhamentos. A resposta obtida é a ampliação contínua da base de fãs, milhares de curtidas e compartilhamentos e centenas de comentários, muitos deles rendendo elogios e propondo relacionamento à Prefs como se ela fosse uma pessoa. Como salienta Corrêa (2003), a web 2.0 potencializa a ação do usuário na rede, através de ferramentas que permitem a expressão e o compartilhamento com outros usuários. Construído com esse intuito, o Facebook possibilita facilmente uma rápida e efetiva distribuição, com a devida referência à fonte, por meio do botão compartilhar. Essa ação, que gera mais dividendos em termos de repercussão, foi usada em 11\% das interações, totalizando 85.043 compartilhamentos.

É o compartilhamento que promove a tão almejada viralização de conteúdo, disseminando-o exponencialmente, despertando o interesse de outras redes e atraindo potenciais novos seguidores. Ele também permite que quem compartilhe na própria linha do tempo ou de um amigo específico, acrescente seu parecer ou apresentação à mensagem, promovendo assim, 
não só o crescimento exponencial da visibilidade da mensagem e da página, mas também sua influência, a partir de um testemunhal ou da anuência. Assim, para além de seguidores, à fan page ainda mais convêm os influenciadores.

Em um processo complexo de influência e legitimação vão se sedimentando popularidade, visibilidade, reputação e autoridade, apontados por Recuero (2009) como valores básicos de constituição da rede a partir da ação dos seus integrantes. Embora 0 tamanho da rede que constitui em torno de si contribua diretamente para a visibilidade e popularidade da instituição, ter uma rede ampla não é suficiente. É o envolvimento dos seguidores que a legitima, podendo consolidar assim sua reputação e autoridade.

Consideramos que a popularidade, caracterizada pela centralidade do nó em relação aos demais, torna a instituição mediadora a mais popular em sua rede institucional. Nesse caso, levamos em conta que os nós que a compõem se reuniram em torno dela e que, em geral, a publicação nas fan pages é restrita aos seus administradores. Se essa caraterística é intrínseca a uma página institucional e pode ser facilmente gerida por meio das ferramentas das mídias sociais, as demais requerem ações estratégicas de relacionamento. A reputação (forma como é percebida pelos sujeitos) é construída na relação, sendo pela consolidação dela que a instituição conquista a autoridade (poder de influência) capaz de legitimar sua fala. Sendo assim, quanto mais interação, mais a rede tem condições de se legitimar e se ampliar.

\section{CONSIDERAÇÕES FINAIS}

Novas perspectivas para a comunicação pública são abertas a partir dos debates e das experimentações geradas em torno da experiência da Prefeitura de Curitiba. 0 tom informal e bem-humorado das postagens da sua página oficial do Facebook tem influenciado outros órgãos e prefeituras, que também estão experimentando uma abordagem mais "leve" para seus temas, em busca de atrair seguidores e promover engajamento. A iniciativa, no entanto, representa mais uma ruptura que um modelo. Traz novos elementos para a constituição do acervo teórico e prático de uso da tecnologia e de novas práticas comunicacionais em prol da aproximação entre governo e sociedade.

0 Facebook é uma plataforma na qual o engajamento sobressai em relação à simples distribuição de conteúdos. Seu foco concentra-se em oferecer possibilidades efetivas de promover envolvimento e experiências. Com isso, suas ferramentas destacam-se sob o ponto de vista relacional, mais que o informacional.

Atenta às perspectivas de relacionamento, a Prefeitura de Curitiba trabalha a experiência decorrente da presença constante, da percepção de uma conexão direta, de um canal aberto e até mesmo de uma vivência que se incorpore mais facilmente a aspectos do cotidiano. Por meio de recursos lúdicos e fáticos de linguagem, ela estimula a comunicação e a sociabilidade, estabelece e testa a conexão e proporciona uma experiência simpática, que gera vínculo afetivo com maior valor agregado que os conteúdos em si.

A aproximação e, sobretudo, a manutenção de um relacionamento, é uma forma de quebrar o distanciamento com 0 órgão oficial do governo executivo. Embora a imagem da prefeitura criada no Facebook não corresponda à rigidez e sisudez inerentes aos órgãos burocráticos estatais, uma perspectiva de aproximação é aberta. Conforme declara Terra (2010) "para ser interessante à audiência, é preciso fazer parte da tribo, criar comunidade". É essencialmente isso o que a Prefeitura de Curitiba faz ao abrir mão de um discurso objetivo e impessoal para adotar uma identidade que a humaniza. 
Como resultado mais plausível dessa iniciativa, obtém um ganho efetivo em aproximação e relacionamento, motivo pelo qual parece-nos relevante em tais iniciativas compreender a importância do gerenciamento do rapport, que é claramente favorecido pelas próprias características inerentes às plataformas de mídias sociais como o Facebook.

Mostrando, no entanto, que essa não é uma fórmula, a prefeitura de Lisboa alcança índices de engajamento consideravelmente superiores aos de Curitiba, mantendo uma postura mais formal. Um importante indicativo se revela a partir de uma característica comum a todas as prefeituras que demonstraram mais altos índices de engajamento: o tom de conversa dado aos textos, o amplo recurso a imagens e a conteúdos fáticos, cuja função é apenas manter a comunicação, na maioria das vezes uma saudação de bom dia ou boa noite, exaltações a aspectos da cidade, comentários sobre o clima etc. Parece pouco, mas suficiente para contribuir para a diluição de barreiras. Tais elementos evidenciam o enfoque na manutenção da proximidade, por meio do apelo afetivo, sugerindo uma tática de brand experience, onde a marca da cidade é valorizada e atua como uma ligação emocional com os públicos, sejam eles cidadãos da própria cidade ou moradores de outras regiões. Os mais distantes geograficamente, ao reverberarem esse discurso também o legitimam para quem vive na cidade.

Tudo isso aponta para abordagens promissoras para futuros estudos, com foco no estabelecimento das própriascondições de relacionamento com os públicos e buscando identificar tanto suas vantagens como observar criticamente suas limitações.

\section{BIBLIOGRAFIA}

BERTOCCHI, Daniela. A narrativa jornalística no ciberespaço: transformações, conceitos e questões. 2006. Dissertação (Mestrado em Ciências da Comunicação) - Universidade do Minho, Braga, Portugal.

CAPPELLA, Joseph N. Mutual influence in expressive behavior: adult-adult and infant-adult dyadic interaction. Psychological Bulletin, v. 89, n. 1, p. 101-132, jan. 1981.

CORRÊA, Elizabeth Saad. Comunicação digital: uma questão de estratégia e de relacionamento com públicos. Organicom - Revista Brasileira de Comunicação Organizacional e Relações Públicas, São Paulo, Gestcorp/ECA-USP, a. 2, n. 3, p. 95-111, 2. sem. 2005.

INOCENCIO, Luana; LIMA, Acsa; NOBRE, Cândida. Marketing de guerrilha e interatividade no ciberespaço: o caso do viral Old Spice. Revista Temática, a. VII, n. 10, out. 2011.

KUNSCH, Margarida M. Krohling. Planejamento de relações públicas na comunicação integrada. 4. ed. - rev., atual. e ampl. São Paulo: Summus, 2003.

MALINOWSKI, Bronislaw. 0 problema do significado em linguagens primitivas. In: OGDEN, Charles Kay; RICHARDS, Ivor Armstrong. O significado do significado. Rio de Janeiro: Zahar, 1972.

RECUERO, Raquel. Curtir, compartilhar, comentar: trabalho de face, conversação e redes sociais no Facebook. Verso e Reverso, v. 28, n. 68, p. 114-124, maio-ago. 2014. 
Redes sociais na internet. Porto Alegre: Sulina, 2009.

SANTAELLA, Lucia. Meios, mídias, mediações e cognição. In: CARAMELA, Elaine. Mídias: multiplicação e convergências. São Paulo: Editora Senac, 2009.

SPENCER-OATEY, Helen. Culturally speaking: managing rapport through talk across cultures. London: Continuum, 2000.

TERRA, Carolina Frazon. Grandes corporações nas redes sociais on-line: um estudo sobre a presença das organizações nas mídias. In: CONGRESSO BRASILEIRO CIENTÍFICICO DE PESQUISADORES DE COMUNICAÇÃO ORGANIZACIONAL E RELAÇÕES PÚBLICAS, IV, Porto Alegre, Abrapcorp, 2010. Disponível em: <www.abrapcorp.org.br/anais2010>. 2010.

Artigo recebido em 16.03.2015 e aprovado em 01.06.2015. 